\title{
Research on the Influence Mechanism of Organizational Communication Quality on Job Performance of the Post-90s Employees:
}

\author{
The Mediating Effect of Job Satisfaction
}

\author{
Ding Yuelan ${ }^{1}$ \\ Department of International Business, Shaanxi Normal \\ University \\ Xi'an, China, 710119 \\ 505257780@qq.com
}

\begin{abstract}
Based on the post-90s employees in China, this paper takes job satisfaction as a mediator, using empirical analysis to explore the relationship among organizational communication quality, job satisfaction and job performance. The results show that organizational communication quality of the post-90s employees has a significant positive effect on job performance, and job satisfaction plays a comprehensive mediating role in the relationship between the two. The conclusions are of great significance for the post-90s employees to improve their job satisfaction and performance.
\end{abstract}

Keywords-Post-90s employees; Organizational communication quality; Job satisfaction; Job performance

\section{INTRODUCTION}

In recent years, the post-90s gradually became the main body of work in the workplace. The study found that the behavior characteristics of post-90s employees are relatively complex, and their human nature hypothesis cannot be simply determined as X-theory, Y-theory, or super-Y theories, but shows the characteristics of partial coincidence and cross-distribution [1]. As a group with unique work values and preferences, how organizations design a matching work environment to meet the needs of employees and motivate them to exhibit positive work behaviors has become a topic of concern for many scholars.

Studies have shown that the post-90s not only have higher requirements for materials, but also have higher requirements for the trust and respect of leaders and a relaxed working environment, which forces organizations to pay attention to the construction of corporate human environment. The research of Raina (2016) [2] revealed that organizational communication quality has a positive impact on job satisfaction and turnover intentions. The research of Sabina (2016) supports the conclusion. Therefore, organizational communication quality provides an environmental basis for organizational behavior. In addition, good performance is affected by the work environment. Mulki (2015) argues that there is a positive effect of guiding leadership and job performance, and the strength of the relationship between them is regulated by power distance.

\author{
Wang Jing ${ }^{2 *}$ \\ Department of International Business, Shaanxi Normal \\ University \\ Xi'an, China, 710119 \\ 1752921293@qq.com
}

The research of Gao He (2015) [3] supports the conclusion. As a result, the work environment affects job performance, and organizational communication quality is the environmental basis of organizational behavior. So will the organizational communication quality affects the job performance of the post-90s employees?

Cognitive behavior theory holds that cognition plays a mediating and coordinating role among cognition, emotion, behavior. And cognitive interprets individual behavior and influences whether individuals take action. Chunga (2017) [4] verified this theory and revealed that the work pressure of employees influence the turnover behavior through the mediation of job satisfaction. The study of Wang Xianya (2013) [5] and others also supported this conclusion. Therefore, this paper attempts to explore whether job satisfaction has an impact on organizational communication quality and job performance.

Will the post-90s employees affect the relationship between organizational communication quality and job performance through job satisfaction? Based on this, the paper attempts to reveal the black-box of organizational communication quality of the post-90s employees and job performance, and enrich the relevant research on organizational communication quality and job performance through the conclusions. 


\section{LITERATURE REVIEW AND RESEARCH HYPOTHESIS}

A. The influence of organizational Communication quality on Job performance of the Post-90s EMPLOYEES

Job performance refers to the integration of work behaviors and work results of employees in the work process, that is, performance $=$ behavior + result. The measurement of job performance is usually based on the two dimensional performance model of Borman and Motowidlol (1993), in which task performance is used to measure employee's personal ability and work knowledge level, and peripheral performance is used to measure the performance related to the surrounding behaviors and activities of the organization. The two-dimensional model of performance is consistent with the research context of this study, so this model is used to carry out the research. In addition, organizational communication quality means that communication is perceived to be timely, accurate and adequate in the organization [6].

There is little attention to the relationship between organizational communication quality and job performance, but it has been shown that organizational communication quality is one of the important factors affecting employee behavior. Iyer (2012) and others based on empirical research of IT employees, has been proved that organizational communication quality has a positive impact on employee participation. Carmem (2015) argued that the internal communication quality of an organization has a positive impact on turnover intentions. Overall, organizational communication quality will have an impact on employee behavior. Therefore, the following assumptions are made:

H1a: Organizational communication quality of the post-90s employees has a positive effect on task performance.

H1b: Organizational communication quality of the post-90s employees has a positive effect on peripheral performance.

\section{B. Intermediary role of job satisfaction in the relationship between organizational communication quality and job performance}

Hoppock points out that job satisfaction is the subjective satisfaction of individuals in both the psychological and physical aspects of their working environment. Smith (1965) associates job satisfaction with remuneration, proposes that job satisfaction is an emotional response to the gap between actual reward and expected reward in the work environment. Most previous studies have confirmed that job satisfaction has a positive effect on job performance. This view was confirmed by Ma Ling (2013) [7] and others. In terms of organizational communication quality and job satisfaction, Andrews (2014) learned from the study of organizational communication needs and job satisfaction of service-oriented companies, shows that the patency and efficiency of information in the enterprise has a significant impact on the job satisfaction of employees.

Wang Yuan (2007) also pointed out that organizational communication quality is not only significantly related to job satisfaction, but also has a significant causal relationship. According to the selection principle of mediator variables proposed by Baron and Kenny (1986) [8], the intermediate variables must be strongly correlated with independent variables and dependent variables. This leads to hypothesis 2 :
H2a: Job satisfaction plays an intermediary role in the relationship between organizational communication quality and task performance.

$\mathrm{H} 2 \mathrm{~b}$ : Job satisfaction plays an intermediary role in the relationship between organizational communication quality and peripheral performance.

Based on the above hypothesis, a theoretical model is established such as Fig. 1.

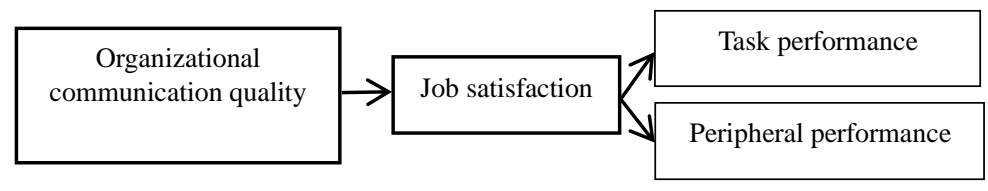

Fig. 1 Theoretical Model

\section{RESEARCH DESIGN}

This paper uses the questionnaire method to collect data, a total of 250 copies were distributed, 218 copies were recovered, 33 invalid questionnaires were excluded, and 185 copies were ultimately retained .The recovery rate of the questionnaire is $87 \%$ and the overall efficiency is $85 \%$.

To ensure the reliability and validity of measuring tools, the study uses maturity scales. The organizational communication quality was measured using a scale developed by Kernan (2002) and others .It consisted of 3 items, Cronbach's $\alpha$ is 0.898 . Job satisfaction was measured using the short Minnesota Job satisfaction scale (MSQ), developed by Dawis (1967) and others. It consists 20 items, Cronbach's $\alpha$ is 0.85.Task performance was measured using task-based performance measurement method, designed by Goodman (1999), contains 7 items, Cronbach's $\alpha$ is 0.826. Peripheral performance was measured using the questionnaire used by Scotter and Motowidle (1996), which contains 7 items, Cronbach's $\alpha$ is 0.858 . Therefore, the internal consistency of the items used in this study meets the requirements.

In addition, studies have shown that demographic variables have an impact on organizational communication quality. In order to avoid the impact of unrelated variables on model validation, this paper will have six control variables, including gender, age of birth, education, nature of work, the number of working years and unit category.

\section{DATA STATISTICS AND ANALYSIS}

\section{A. Reliability and validity}

The reliability of this study is expressed by internal consistency, that is, Cronbach's $\alpha$. As shown above, all scales have good reliability and meet the needs of research.

Since the scales used in this paper are validated maturity scales, they have good content validity. To further improve accuracy, the structural validity of the scales were tested. The results showed that the KMO values were all greater than 0.7 , indicating that the sample data was suitable for factor analysis. Bartlett's sphericity test has a significance of 0.000 , indicating that there are common factors among the mother matrix correlation matrixs, and the variables are not independent of each other. The questionnaire has a good structural validity. 


\section{B. Descriptive Statistics and Related Analysis}

The analysis of major variables using the one-way analysis of variance revealed that both organizational communication quality and job satisfaction were significantly related to job performance (results are shown in Table 1). In addition, there are significant correlations between the three variables of age of birth, education, working years and job performance. The influence of statistical variables must be controlled when using hierarchical regression model to analyze the correlation of each variable.

TABLE I MEAN, VARIANCE AND CORRELATION OF VARIABLES

\begin{tabular}{cccc}
\hline Variables & $\begin{array}{c}\text { Organizational } \\
\text { Communication Quality }\end{array}$ & Job Satisfaction & Job Performance \\
\hline $\begin{array}{c}\text { Organizational } \\
\text { Communication Quality }\end{array}$ & 1 & & \\
& & 1 & 1 \\
Job Satisfaction & $0.816^{* *}$ & $0.883^{* *}$ & 3.70 \\
Job Performance & $0.718^{* *}$ & 3.69 & 0.87 \\
\hline Mean & 3.73 & 0.96 & Note:*means significant at 0.05 level, **means significant at 0.01 level, the same as below.
\end{tabular}
The control variable was introduced into the regression

\section{Hypothesis Testing}

This paper examines the main effects and mediating effects in three steps: (1)The influence of independent variable on the dependent variables. The control variable is introduced into the regression equation, and then the independent variable is added to analyze the influence of organizational communication quality on task performance and peripheral performance. (2) The influence of independent variable on the mediator variable. equation, and then the independent variable was added to analyze the effect of organizational communication quality on job satisfaction. (3) Mediation effects. The independent variable and control variable are introduced into the regression equation, then the intermediary variable is added to analyze the influence of organizational communication quality and job satisfaction on task performance and peripheral performance. The hierarchical regression results are shown in Table 2.

TABLE II Hypothesis Test Results (N=185

\begin{tabular}{|c|c|c|c|c|c|c|c|c|}
\hline \multirow{4}{*}{ Category } & \multirow{2}{*}{\multicolumn{2}{|c|}{$\begin{array}{c}\text { Job } \\
\text { Satisfaction }\end{array}$}} & \multicolumn{6}{|c|}{ Job Performance } \\
\hline & & & \multicolumn{3}{|c|}{ Task Performance } & \multicolumn{3}{|c|}{ Peripheral Performance } \\
\hline & Model & Model & Model & Model & Model & Model & Model & Model \\
\hline & 1 & 2 & 3 & 4 & 5 & 6 & 7 & 8 \\
\hline Birth Age & -0.584 & -0.267 & $-0.897^{*}$ & -0.648 & -0.446 & -0.873 & -0.631 & -0.432 \\
\hline Education & -0.356 & $-0.155^{*}$ & $0.413^{* *}$ & -0.255 & $-0.137^{*}$ & $0.409^{*}$ & -0.256 & -0.139 \\
\hline Working Years & -0.014 & -0.037 & $-0.03^{* *}$ & -0.021 & 0.007 & -0.017 & -0.034 & -0.007 \\
\hline $\begin{array}{c}\text { Organizational } \\
\text { Communication Quality }\end{array}$ & & $0.706^{* *}$ & & $0.554^{* *}$ & -0.009 & & $0.538^{* *}$ & -0.016 \\
\hline Job Satisfaction & & & & & $0.757^{* *}$ & & & $0.748^{*}$ \\
\hline $\mathrm{R}^{2}$ & 0.201 & 0.712 & 0.339 & 0.661 & 0.829 & 0.325 & 0.632 & 0.799 \\
\hline$\Delta \mathrm{R}^{2}$ & 0.183 & 0.704 & 0.325 & 0.651 & 0.824 & 0.310 & 0.622 & 0.793 \\
\hline $\mathrm{F}$ & $\begin{array}{l}11.2 \\
88\end{array}$ & $\begin{array}{l}88.4 \\
26\end{array}$ & $\begin{array}{l}23.12 \\
3 *\end{array}$ & $\begin{array}{l}69.74 \\
0\end{array}$ & $\begin{array}{l}144 . \\
207\end{array}$ & $\begin{array}{c}21 . \\
690\end{array}$ & $\begin{array}{l}61.6 \\
04 *\end{array}$ & $\begin{array}{c}118 . \\
132\end{array}$ \\
\hline
\end{tabular}

According to model 3 , the birth age had a significant negative effect on task performance $(\beta=-0.897, \mathrm{p}<0.01)$, education had a positive effect on task performance $(\beta=0.413$, $\mathrm{p}<0.01$ ), and working years might have a negative effect on task performance $(\beta=-0.03, \mathrm{p}<0.01)$. According to model 6 , birth age has a significant negative effect on peripheral performance $(\beta=-0.873, p<0.05)$, education has a positive effect on peripheral performance $(\beta=0.409, \mathrm{p}<0.01)$, and working years may have a negative effect on peripheral performance $(\beta=-0.017, \mathrm{p}<0.01)$.

From model 4 and model 7, organizational communication quality had a positive effect on task performance and peripheral performance $(\beta=-0.554, \mathrm{p}<0.01 ; \beta=-0.538, \mathrm{p}<$ $0.01)$. Assuming that $\mathrm{H} 1 \mathrm{a}$ and $\mathrm{H} 1 \mathrm{~b}$ are supported. According to model 2, organizational communication quality had a significant positive effect on job satisfaction $(\beta=0.706, \mathrm{p}<$ 0.01 ). From model 5 and model 8 , after the mediation variable is added, the positive effect of organizational communication quality on task performance is affected and becomes insignificant $(\beta=-0.009)$, and the positive effect on peripheral performance is affected and becomes insignificant $(\beta=-0.016)$, assuming $\mathrm{H} 2 \mathrm{a}, \mathrm{H} 2 \mathrm{~b}$ are supported. 


\section{CONCLUSION}

In general, the empirical results prove the research hypothesis proposed in this paper. Specifically:

First, the influence of statistical variables on performance of the post-90s employees is mainly reflected in the birth years, education and working years. Therefore, as a knowledge worker, the study of the relationship between organizational communication quality and job performance is of practical significance.

Second, organizational communication quality has a positive impact on performance of the post-90s. Therefore, in the practice of organizational management, it is possible to establish a flat organizational structure, shorten the spatial distance between managers and grassroots employees, and improve the organizational communication quality.

Third, job satisfaction plays an entirely mediating role in the relationship between organizational communication quality and job performance. Therefore, managers can establish diversified information communication channels according to the preferences of the post-90s employees to improve their job satisfaction and job performance.

The conclusion of this paper provides the basis for opening the "black box" between organizational communication quality and job performance, enriches the research on the effect of organizational communication quality in China, and expands the understanding of the factors affecting job performance. But there are still the following limitations: (1) It is confirmed that organizational communication quality has a positive effect on job satisfaction, but some studies have found that there may be a mutual influence between the two, and this study has not been proved; (2) This paper has not carried out an analysis of the dimensions of job satisfaction. The follow-up study can further explore whether the different dimensions of job satisfaction are still completely mediated in the relationship between organizational communication quality and job performance.

\section{REFERENCE}

[1] Rong Pengfei. Management of Post-90s Employees based on Human Nature Hypothesis [J]. Modern Management Science,2013(2):91-93.(In Chinese)

[2] Reeta Raina, Deborah Britt Roebuck. Exploring Cultural Influence on Managerial Communication in Relationship to Job Satisfaction, Organizational Commitment, and the Employees' Propensity to Leave in The Insurance Sector of India [J]. International Journal of Business Communication, 2016(1):97-130.

[3] Gao Ke, Li Tingting, Duan Hui. An Empirical Study on the Impact of Abusive Management on Job Performance [J]. Enterprise Economy, 2016(5):104-110. (In Chinese)

[4] Eun Kyoung Chung, Yeseul Jung, Young Woo Sohn. A Moderated Mediation Model of Job Stress, Job Satisfaction, and Turnover Intention for Airport Security Screeners [J]. Safety Science, 2017, 6(5): 89-97.

[5] Wang Xianya. A Study on the Relationship Between Emotional Intelligence and Job Performance -- The Intermediary Role of Job Satisfaction [J]. Management Modernization, 2013(3): 60-62. (In Chinese)

[6] Goldhabergm, Krivonospd. The ICA Communication Audit: Process, Status, Critique $[\mathrm{J}]$. The Journal of Business Communication, 1977(15):42.

[7] Ma Ling. The Relationship Between Job Satisfaction, Organizational Commitment and Job Performance [J]. Human Resources, 2013(5): 68-71. (In Chinese)

[8] Baron R.M, Kenny D.A. The Moderatot-Mediator Variable Distinction in Social Pyschological Research: Conceptual, Strategic, and Statistical Considerations [J]. Journal of Personality and Social Psychology, 1986(6):1173-1182. 